Témoigner Témoigner. Entre histoire et mémoire

Getuigen Revue pluridisciplinaire de la Fondation Auschwitz

$125 \mid 2017$

Histoire et mémoire de la persécution des

homosexuel·le's par les nazis

\title{
De Tweede Wereldoorlog herdenken in Oekraïne: eenheid en versplintering
}

Mémoire(s) en Ukraine: de l'unité à la diversification

\section{Frédéric Crahay}

Traducteur : Anneleen Spiessens

\section{(2) OpenEdition}

Journals

\section{Édition électronique}

URL : https://journals.openedition.org/temoigner/6295

DOI : 10.4000/temoigner.6295

ISSN : 2506-6390

Cet article est une traduction de :

Mémoire(s) en Ukraine : de l'unité à la diversification - URL : https://journals.openedition.org/

temoigner/6065 [fr]

Éditeur :

Éditions du Centre d'études et de documentation Mémoire d'Auschwitz, Éditions Kimé

Édition imprimée

Date de publication : 1 octobre 2017

Pagination : 40-49

ISBN : 978-2-930953-01-4

ISSN : 2031-4183

Référence électronique

Frédéric Crahay, «De Tweede Wereldoorlog herdenken in Oekraïne: eenheid en versplintering»,

Témoigner. Entre histoire et mémoire [Online], 125 | 2017, Online op 24 décembre 2021, geraadpleegd op 03 février 2022. URL: http://journals.openedition.org/temoigner/6295 ; DOI: https://doi.org/10.4000/ temoigner.6295 


\section{DE TWEEDE HERDENKEN EENHEID EN}

$\rightarrow$ Frédéric Crahay Stichting Auschwitz Vortaling uit het Frans:

$\mathrm{O}$

raïne kent een lange en rijke geschiedenis. De jaren dertig en vertig vormen dar geen uitzondering op. Na kort van een schijnautonomie te hebben genoten aan het einde van de Eerste Wereldoorlog wordt Oekraïne, dat etymologisch gezien 'grens' betekent opgeslokt door de Sovjet-Unie, waar de Russen het voor het zeggen hebben Desondak Desondanks kan het idee van een onafhankelijke staat, opgevat en aangewakkerd door mannen als Symon Petjura, op aanhangers bljven rekenen. Om het Oekraiense volk onder de duim te houden lokt Stalin in 1932 en 1933 resoluut ent de term Holodomor met de tern Holodomor en benadrukken het genocidaire karakter ervan. Al wercte de onvang van de ranp word zels in het westen erkend sinds de De kand Solzjenitsyns Goelag Aichipel in 1943.

De komst van nazitroepen in juni 1941 verdeelt de Oekraïners dan ook in verschillende kanpen onalsten onder leiding van ideoloog Stepan Bandera, kiest voor collaboratie met de Duitse troepen en droom tegelijkertijd van een onahankelijk Oekra-

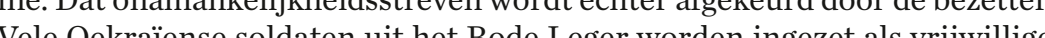
Vele Oekraiense soldaten uit het Rode Leger worden ingezet als vijwillige werk ilf Jodilliger gen de strijd koers. Een met de naz"s maar vaart wel een racical anticonnmistische koers. Een derde groep bundelt de krachten met het Rode Leger tot aan diens de Sovjet-Unie Tot 1954 blijven de Oekraïense onfhankelijkheidsstrijders de Sovjet-Unie. Tot 1954 bljven de Oeknillese

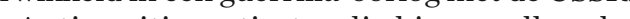

Antisemitisme tiert welig binnen alle gelederen. De Joodse bevolking wordt ervan beticht vanst door kogels' uit, Ook in de Baltische staten, Polen en de beze delo

\section{WERELDOORLOG IN OEKRAINE: VERSPLINTERING}

van de Sovjet-Unie zijn de Einsatzgruppen actief, maar de executies met vuurwarpens zullen toch voor altijd verbonden blijven met Babi Jar, de ravijn vlakbij Kiev waar op 29 en 30 september 194133771 Joden het ongeveer anderhalf miljoen Oekraiense Joden werden vermoord tijdens de invasie vande Sovjet-Un

De herinnering aan de periode 1931-1945 is enorm versplinterd in het Oekraïne van vandaag. Een eerste herinnering Zo ontston memorialen opgerichtter verdenking an de Holodo Sinds de jaren 2000 kn comuitistischet iltgenoorde Joodse vallo zo mogelijk hot Oekraiense martelaarboek. Op een het geval voor de Roma en Sintidie door de nazis werden uitreroid vak met de hulp van Oekrä̈ den intoro dens de Twar het barbeid dankzij het work van de verenising Unum, die onder leiding van priester Patrick Desbois In Kiev probert het Ukrainin Center for Holocast Studies vabert het Uly Studies van Ait pijnlijke verleden, marliek bewust te maken van dit pijnlijke verleden, maar de subsidies uit het buitenland. levenlieten. Historicischattendat tussen 1941en 1944 aanzet tot memorialisering kwam er onder invloed van de Sovjets in 1945, maar sinds de Oekraiense onafhandening van Zo Holon mor Unum, die onder leiding van priester Patric Desbois
Anderzijds zagen we dan weer hoe tijdens de UEFA up van 2012 gezamenlijk georganiseerd door Polen en Oelaine, op rieuw nazymben

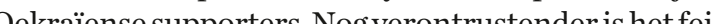
etratitis zich siteeds vater on the 

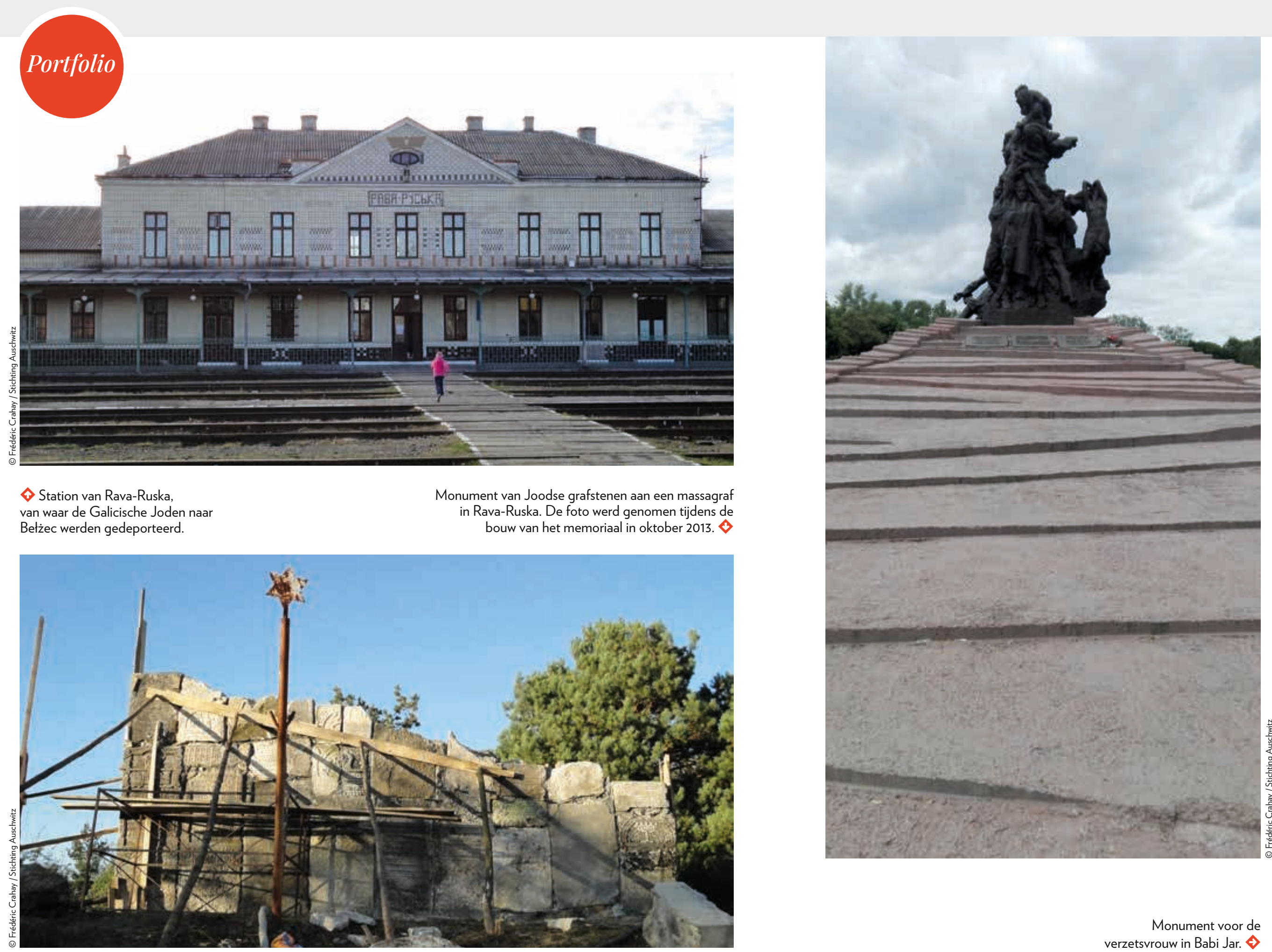

Sovjetmonument uit 1976 in Babi Jar. De

inscripties in het Russisch, Oekraiens en Jiddisch

inscripties in het Russisch, Oekraiens en Jiddisch

de slachtoffers voornamelijk Joods waren.

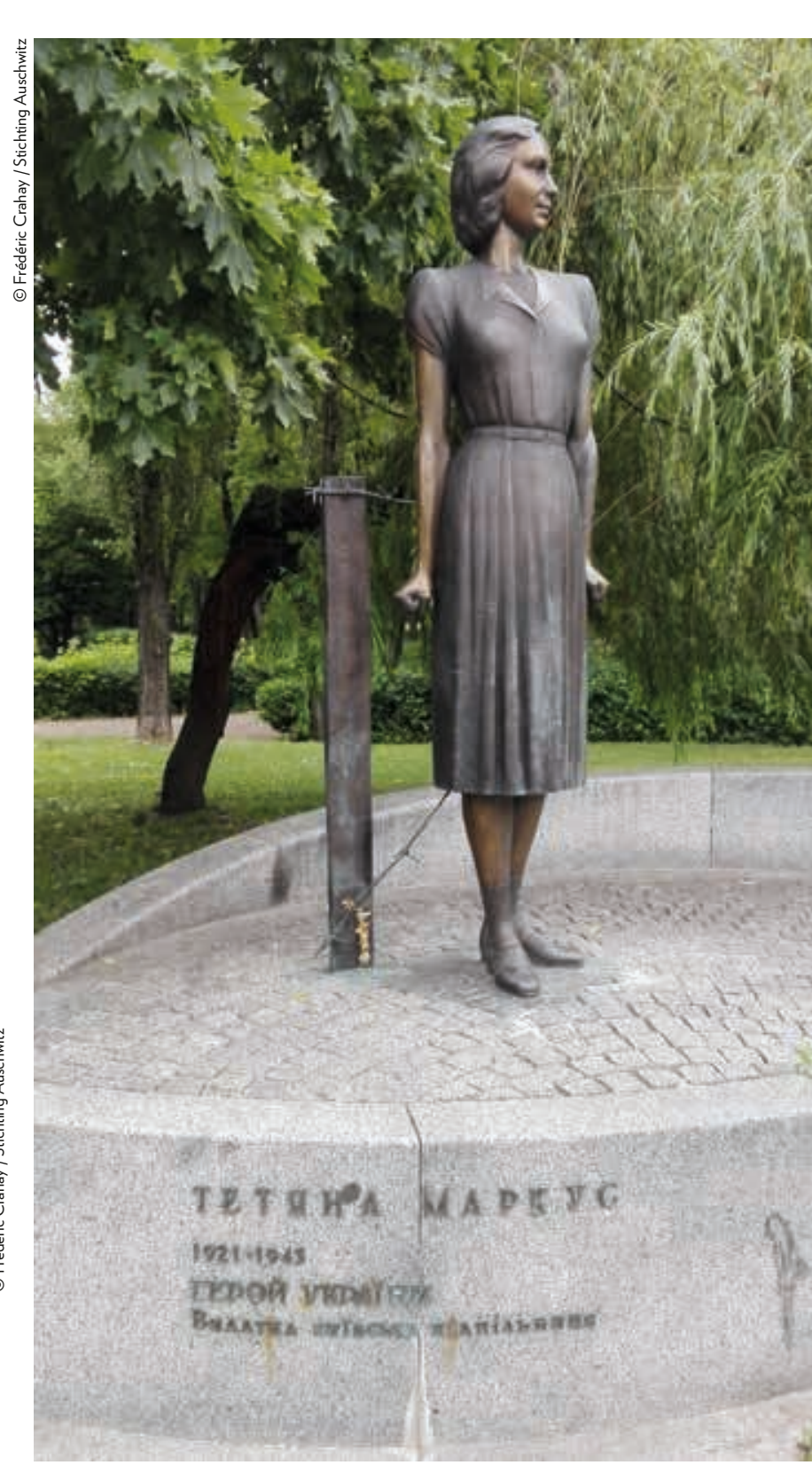




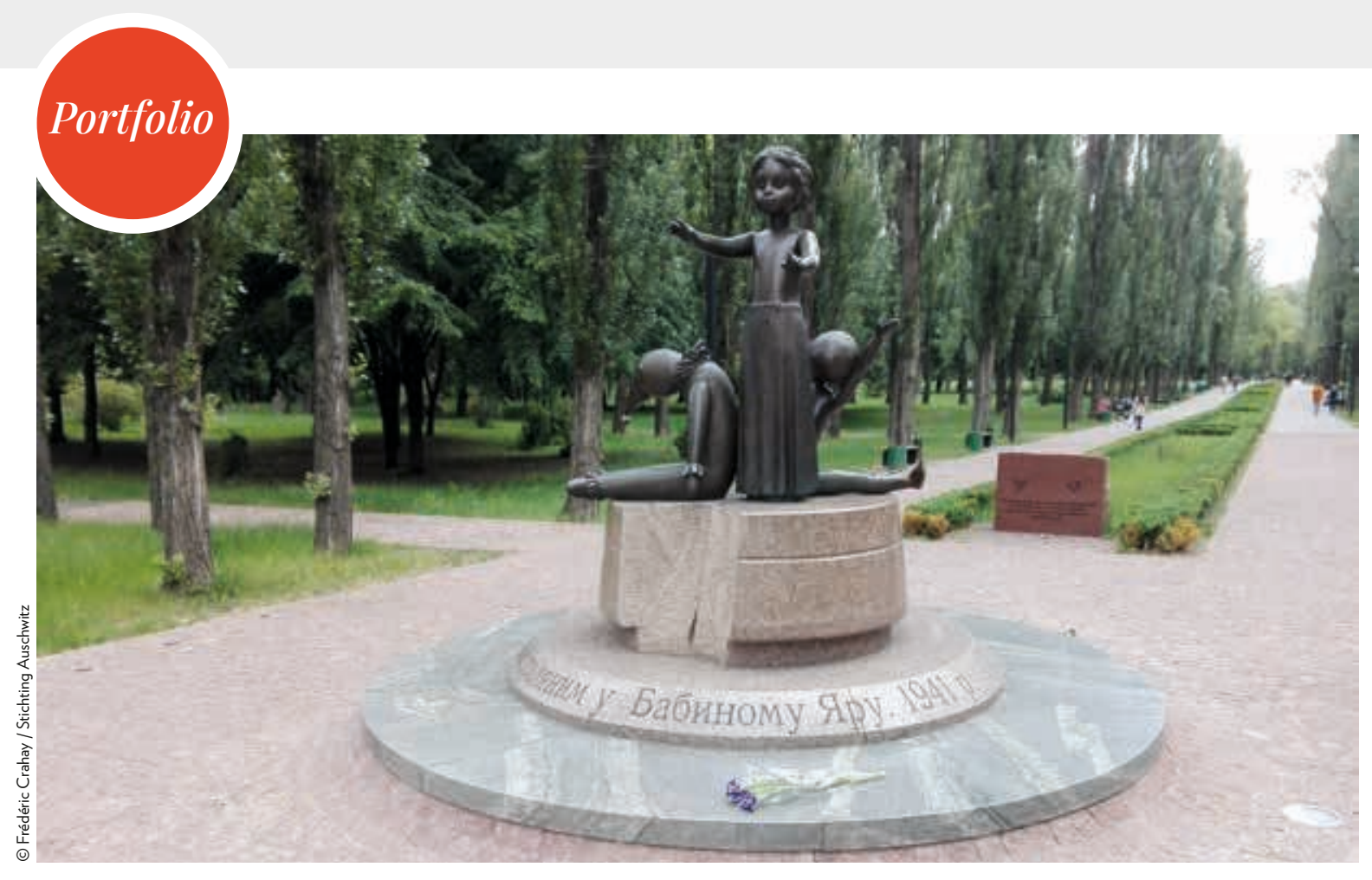

$\checkmark$ Monument voor de kinderen die slachtoffer werden van de genocide in Babi Jar. Het werd in 2001 bijgeplaatst.

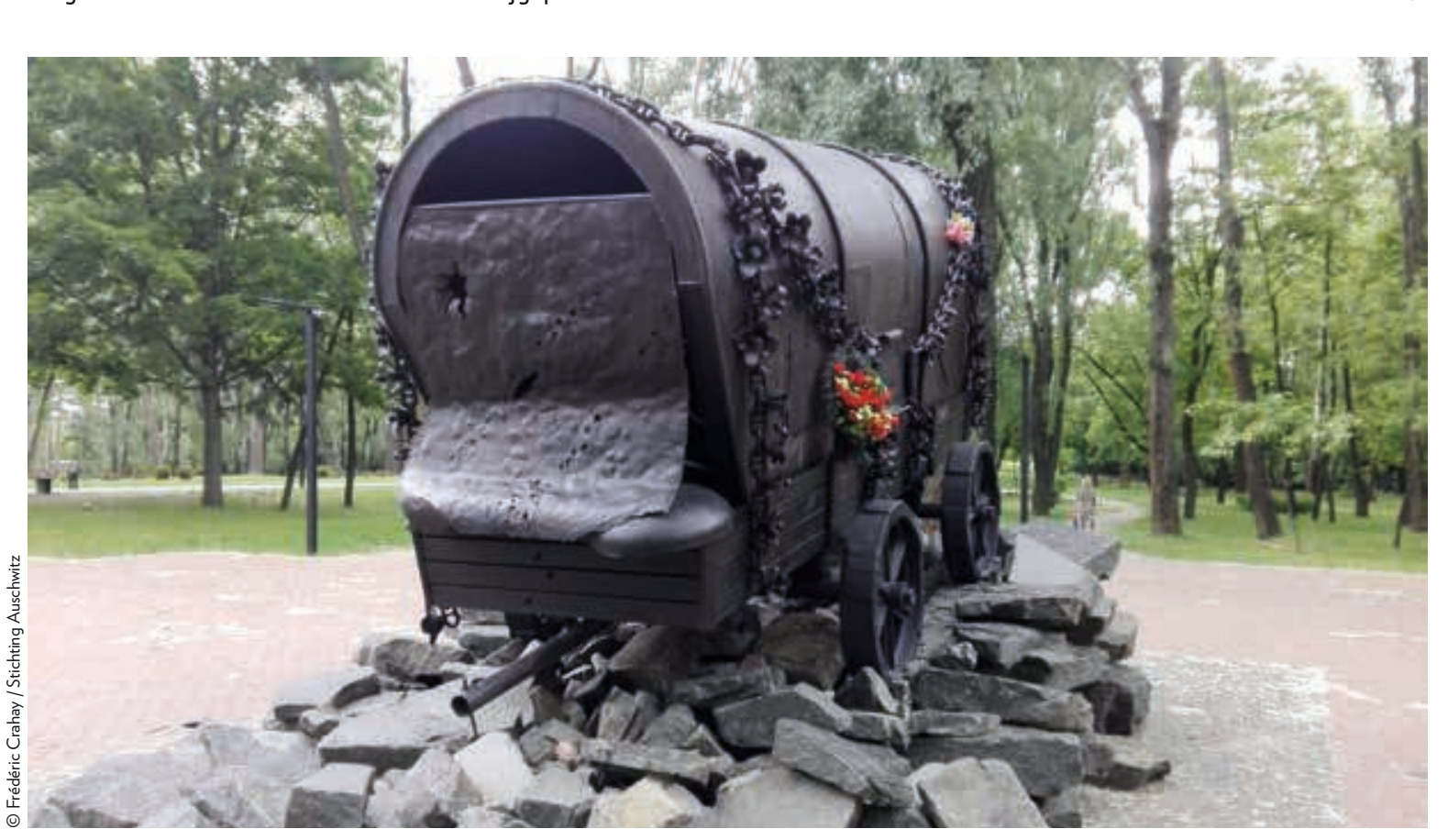

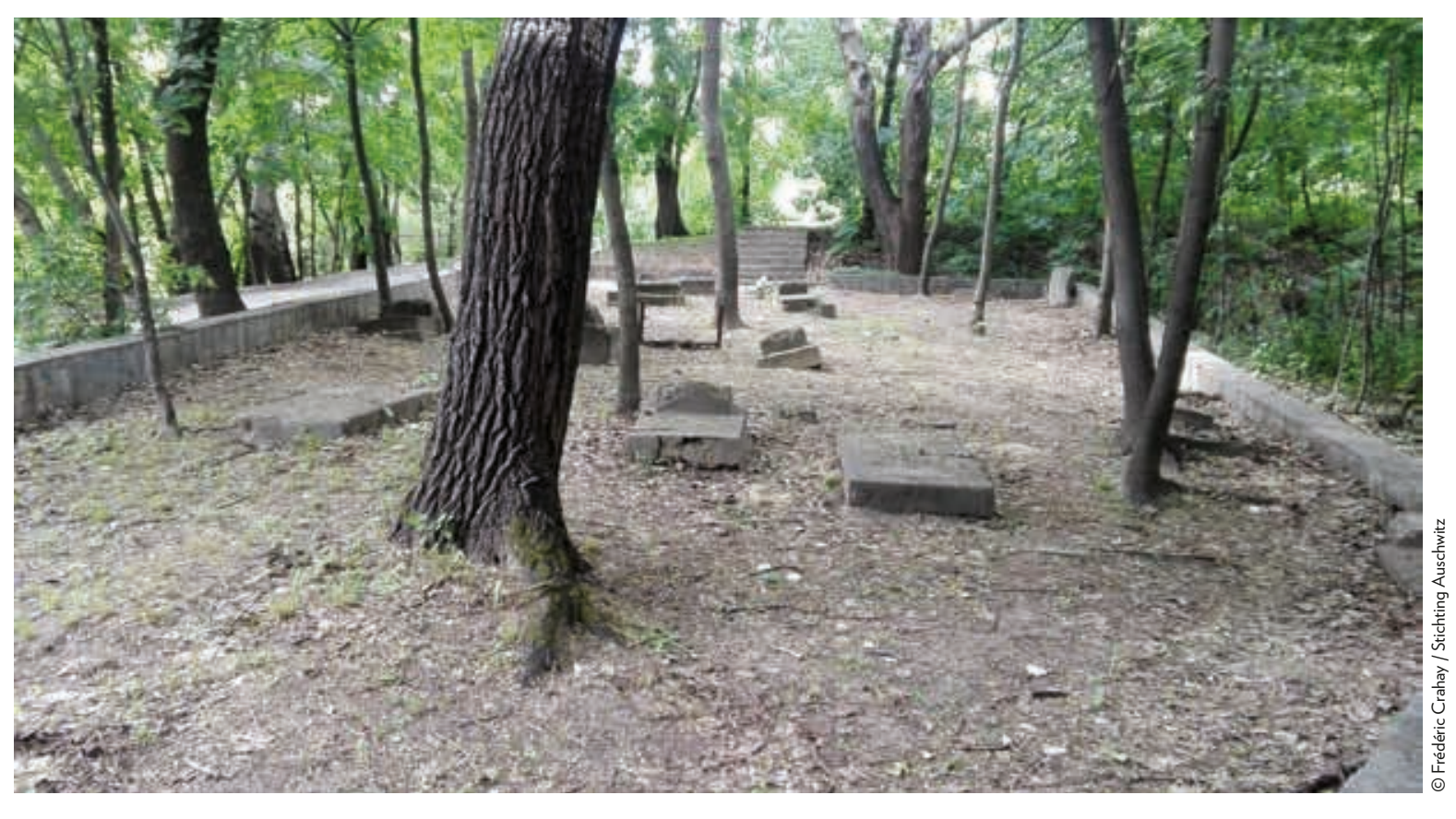

$\checkmark$ Babi Jar, restanten van het oude Joodse kerkhof dat tijdens de Shoah werd vernietigd.

Restanten van het Joodse
kerkhof van Lviv. $\diamond$

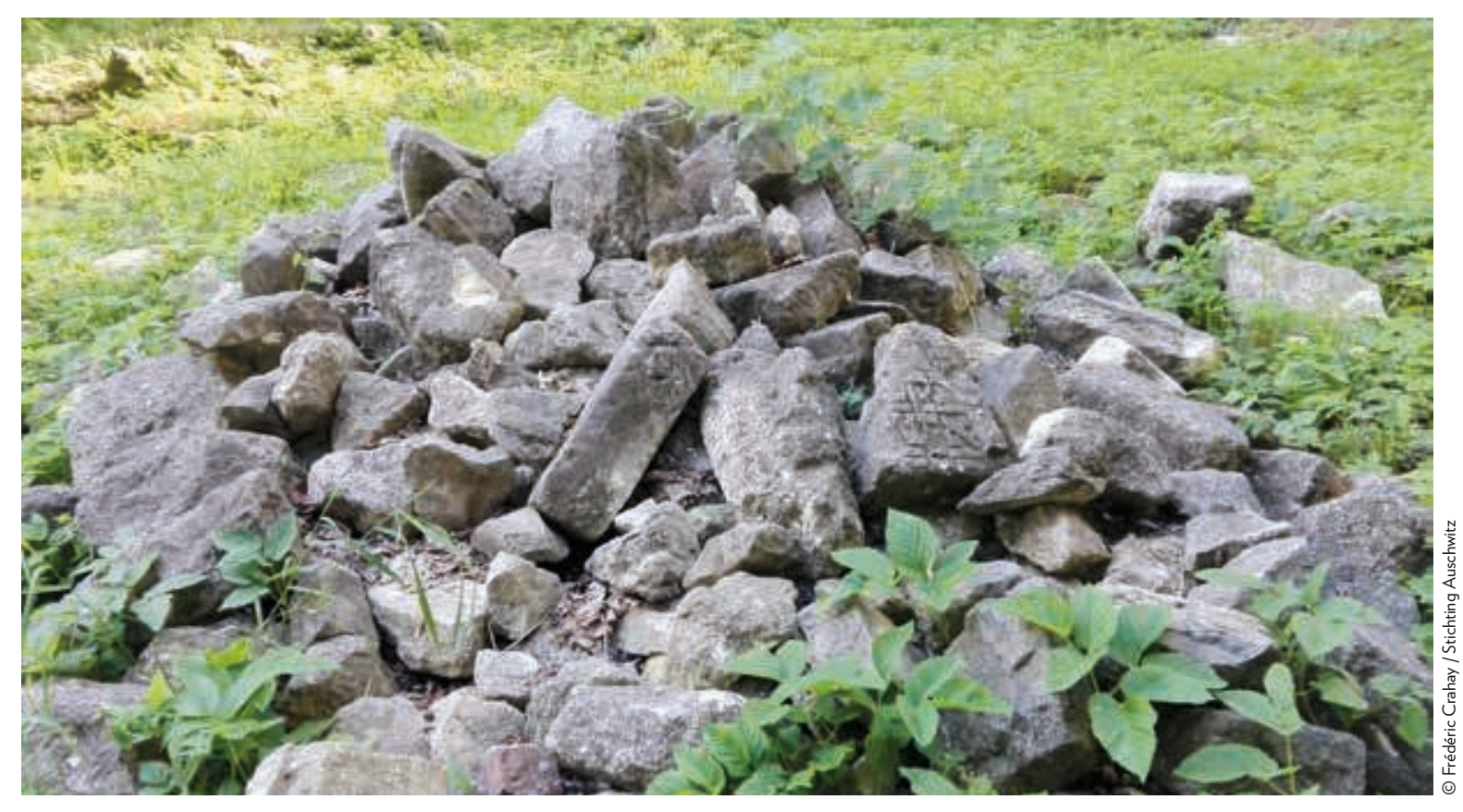




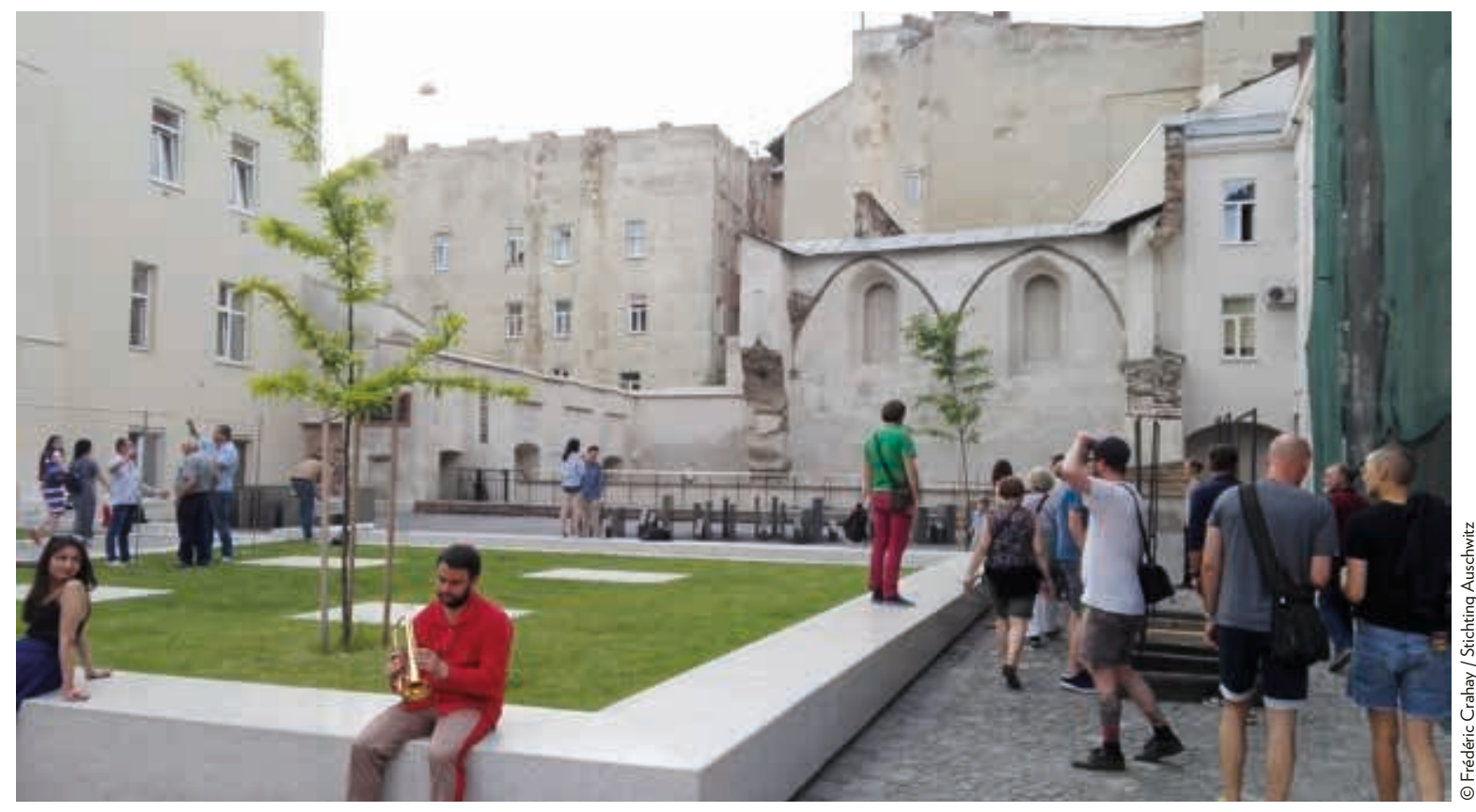

$\checkmark$ Herdenkingsmonument van de 'Gouden Roos'-

Detail van het herdenkingsmonument synagoge in Lviv, die werd vernietigd door de nazi's. van de 'Gouden Roos'-synagoge in Lviv.
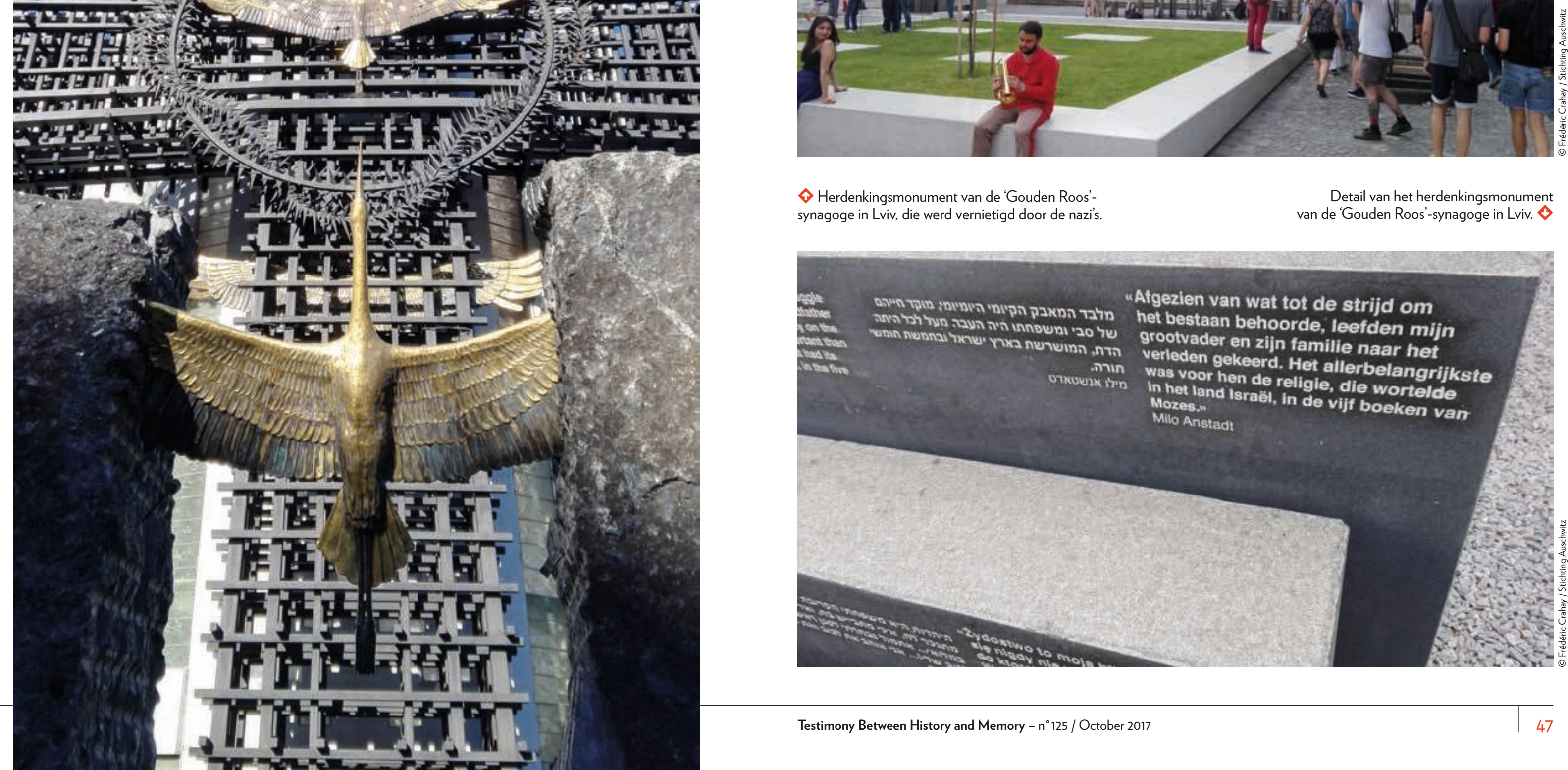


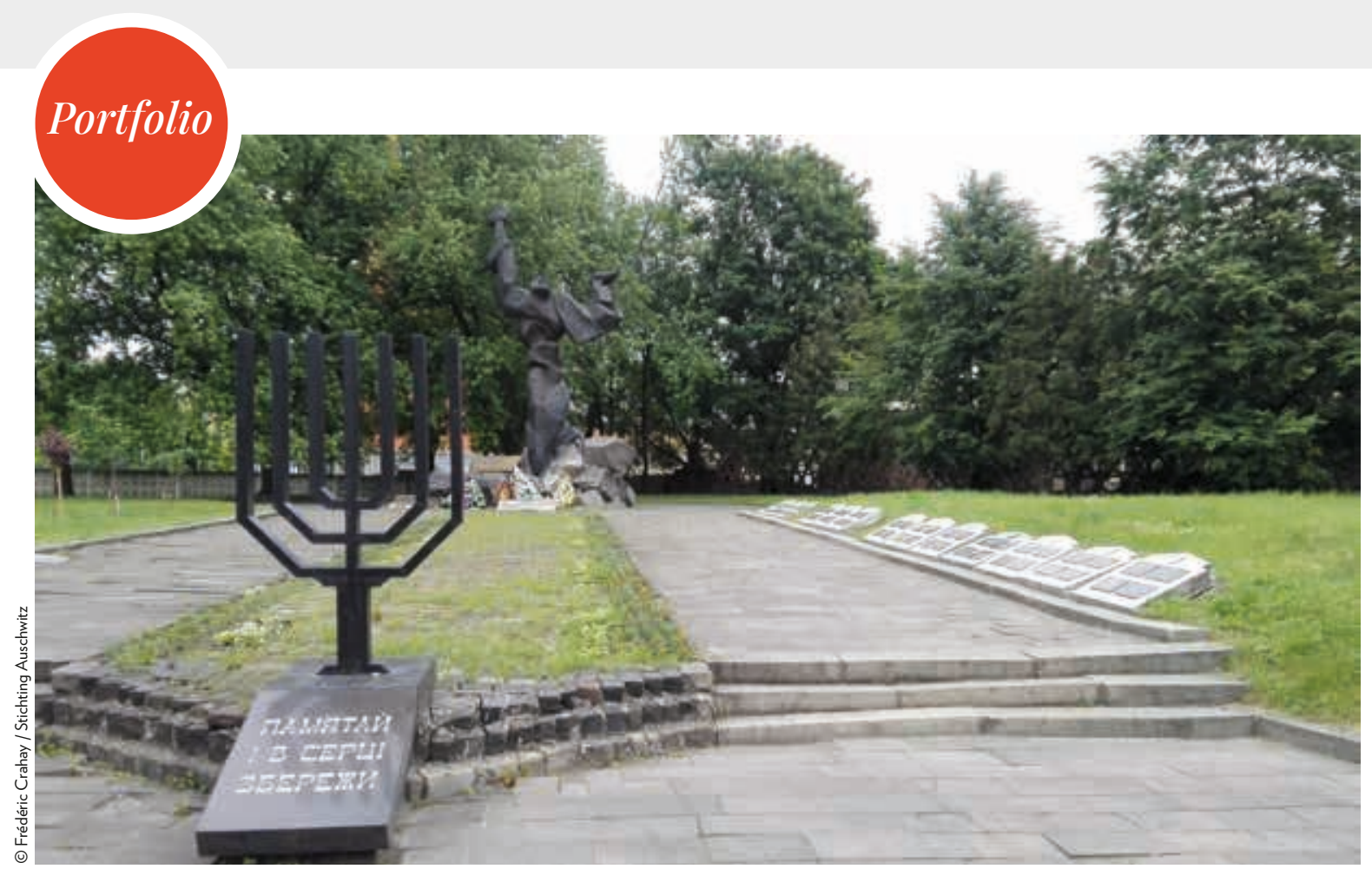

Memoriaal voor de slachtoffers van

Graf van de Oekraiense soldaten van de SS-divisie
'Galizien' op het kerkhof van Lychakiv.

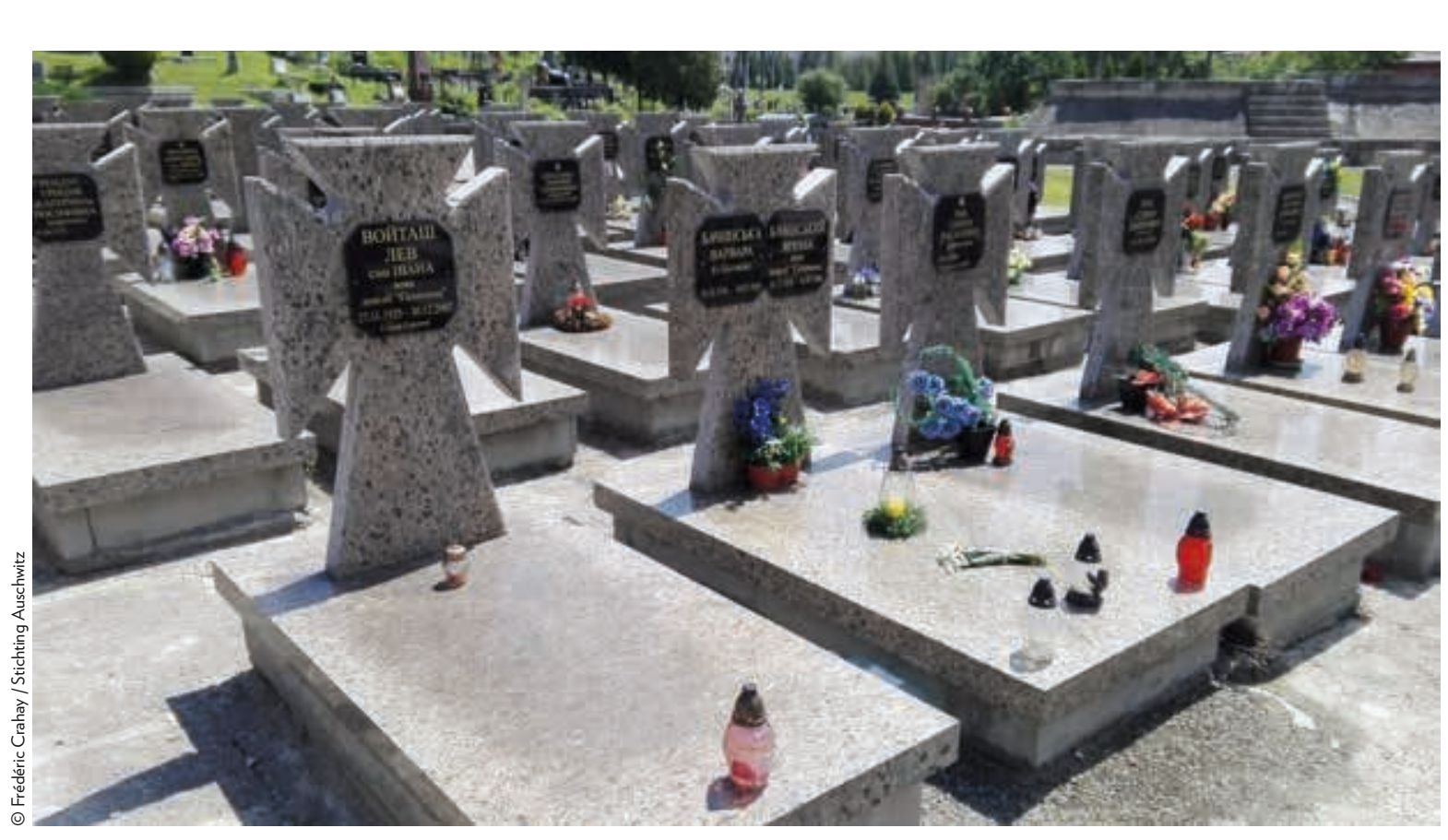

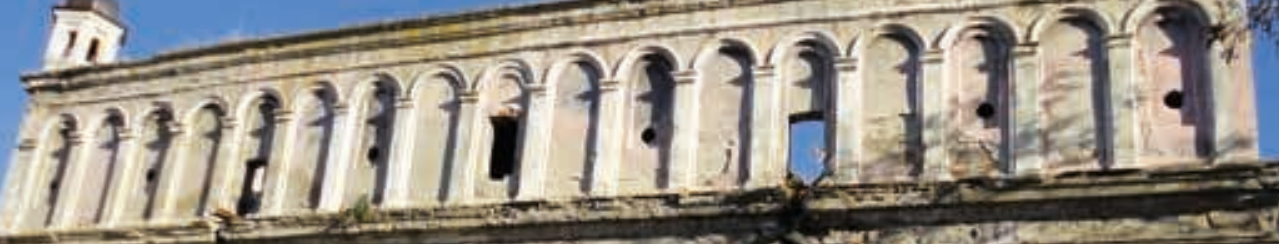

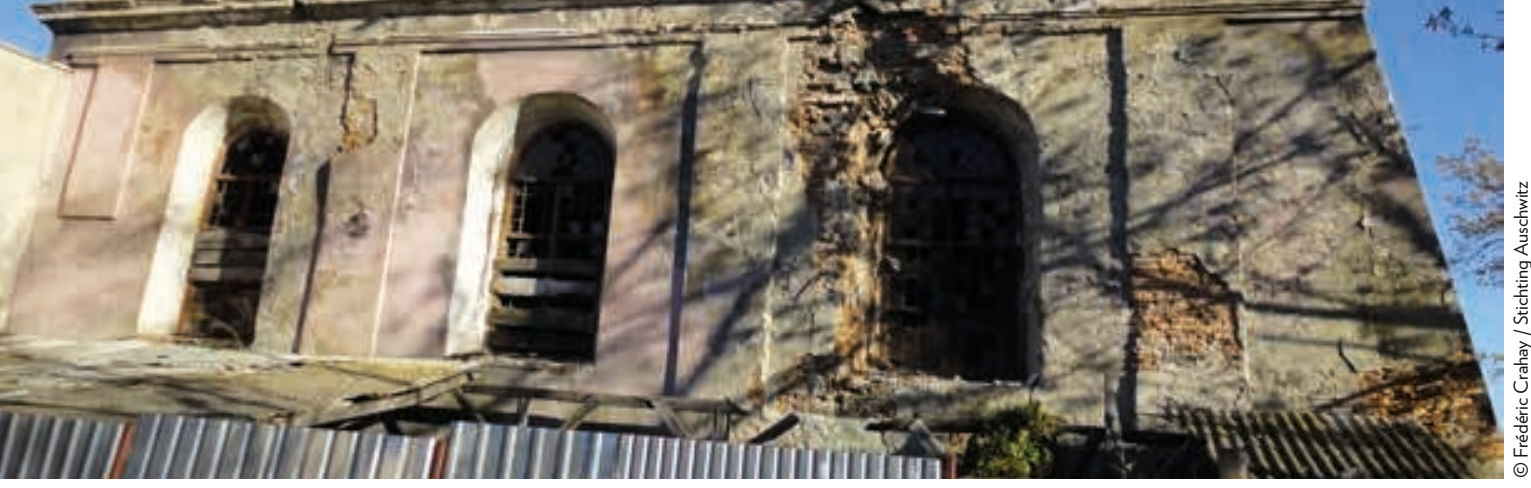

$\diamond$ Voormalige synagoge

Synagoge van Drohobyts,

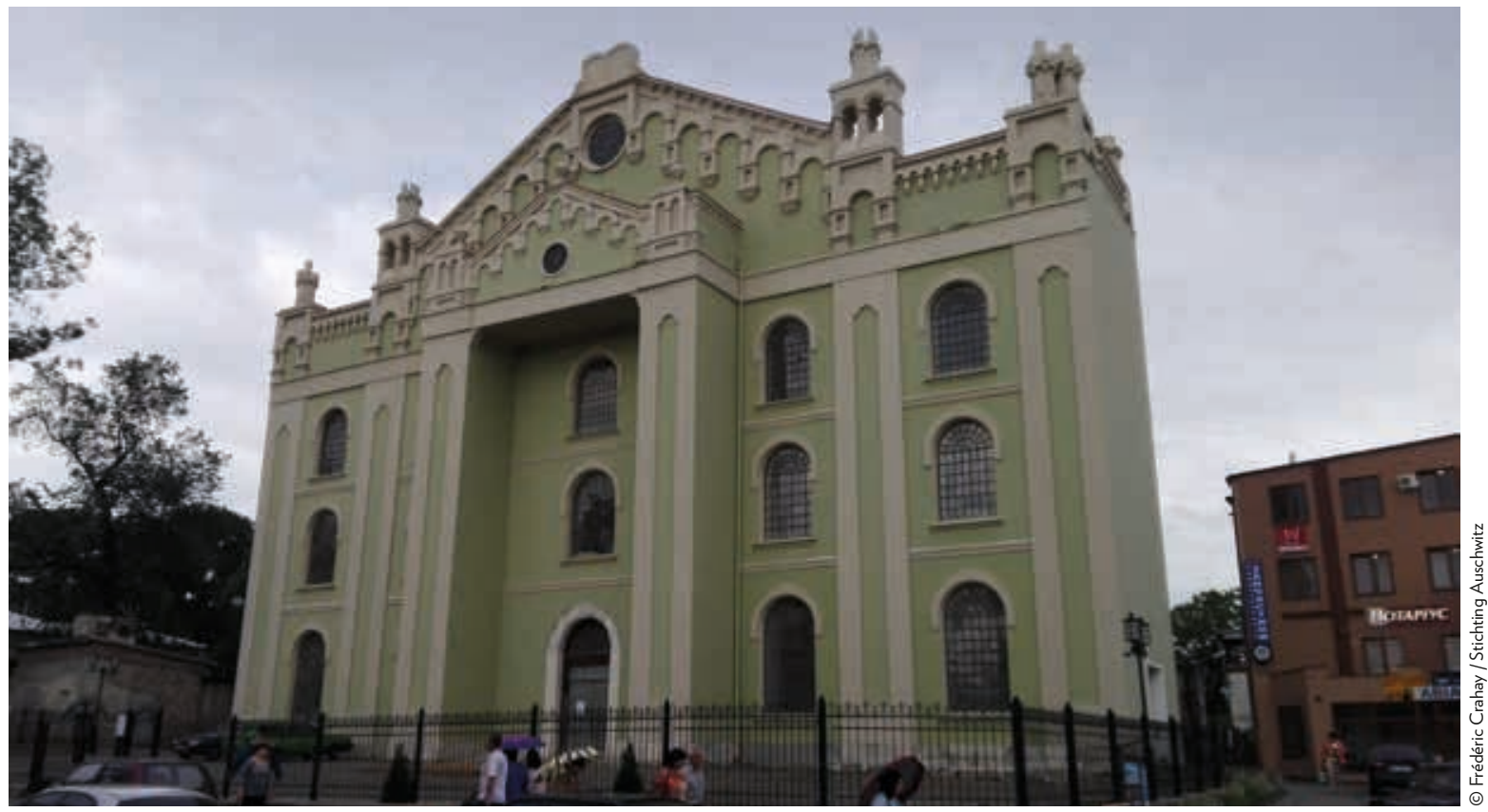

